\title{
Effect of Repeated Weld Repairs on Microstructure and Mechanical Properties of Heat-Affected Zone in CA6NM Stainless Steel
}

\author{
Peng Liu $\mathbb{D}^{1,2}$ Jien Ma ${ }^{1},{ }^{1}$ Youtong Fang $\mathbb{D}^{1},{ }^{1}$ Bowen Xu $\mathbb{D}^{1},{ }^{1}$ and Lin Qiu ${ }^{1}{ }^{1}$ \\ ${ }^{1}$ College of Eledtrical Engineering, Zhejiang University, Hangzhou, Zhejiang 310000, China \\ ${ }^{2}$ Shenyang Blower Group Co.,Ltd.,, Shenyang, Liaoning 110869, China \\ Correspondence should be addressed to Jien Ma; majien@zju.edu.cn
}

Received 24 August 2021; Accepted 7 February 2022; Published 3 March 2022

Academic Editor: Wei Liu

Copyright ( $\odot 2022$ Peng Liu et al. This is an open access article distributed under the Creative Commons Attribution License, which permits unrestricted use, distribution, and reproduction in any medium, provided the original work is properly cited.

\begin{abstract}
The low-carbon martensitic stainless steel CA6NM is widely used in the impellers of hydroelectric and nuclear power units due to its advantages of high hardness, corrosion fatigue strength, and good fracture toughness. In order to analyze the number of repair welding times on the properties of heat-affected zone (HAZ, the most unstable area of welded joint property) in CA6NM, the microstructure and mechanical properties of HAZ with once-repaired welds (1R) and twice-repaired welds (2R) were tested. Through data analysis, the following conclusions are drawn for welded joints: (1) the grain size of HAZ with a different number of repair welding processes is smaller than that of the base material; (2) the density of texture concentration is reduced and the directionality is not obvious; (3) the density of twins and dislocations are increased; (4) the hardness and impact energy of HAZ of the $1 \mathrm{R}$ and $2 \mathrm{R}$ specimens are higher than that of the base material.
\end{abstract}

\section{Introduction}

With the development of society and the progress of science and technology, the demand for electricity is consistently increasing. At present, access to social electricity is mainly dependent on fossil resources. In the process of transforming these resources into electricity for use by various industries in society, a large variety and amount of toxic and hazardous substances are generated, which will pollute the environment. With the increase of environmental pollution and the greenhouse effect, the frequency of extreme weather is also on the rise. These phenomena have brought significant risks to people's lives and property. Therefore, many countries are investigating new clean energy resources to reduce pollution and improve the living environment. As a new type of clean energy, nuclear energy technology has been paid attention to around the globe, and relevant investments have gradually increased. Accordingly, the installed capacity of nuclear power generation has shown an increasing trend in various countries. Although nuclear power generation is a clean energy resource, the safe operation of nuclear power plants and nuclear radiation protection remain issues of general concern. These have promoted the continuous development of nuclear power generation technology and the improvement of the construction and operation of nuclear power plants.

Nuclear pump is a key component of a nuclear power plant, and its quality is directly related to the safe operation of such power plant. The main body of a nuclear pump consists of a pump casing and an impeller. Based on the current standards, the impeller is usually cast from CA6NM stainless steel. This is because this material has high hardness and corrosion fatigue strength, good fracture toughness, and excellent weldability at room temperature and below [1]. During the casting process, the metal liquid will flow quickly in the mold and have a violent reaction with the mold. Although the casting process can be optimized, this process will inevitably produce certain defects, such as porosity and inclusion. Therefore, all castings have relevant standards regarding the allowed number and size of defects contained 
within them during the acceptance process. When the size of defects exceeds the standard requirements, certain repair measures should be taken to remove those defects and make the product meet the requirements. Therefore, repair welding technology is widely used in casting procedures. $[2,3]$.

Since CA6NM stainless steel is formed by casting, a large number of scholars have carried out research on its as-cast structure and properties, especially its corrosion resistance $[4,5]$. With the increasing number of applications where CA6NM stainless steel needs to be connected, its welding method and technology has also attracted scholars' attention. Sarafan et al. [6] used EB to weld $60 \mathrm{~mm}$ thick CA6NM with a single pass without filler metal. The welded joint of CA6NM exhibited a narrow fusion zone and a series of distinct yet very small heat-affected zones (HAZ) with different microstructural characteristics. Mirakhorli et al. [7] used laser-arc welding to weld $10 \mathrm{~mm}$ thick CA6NM in a butt joint. The evaluation of the mechanical properties of welded joint after $600^{\circ} \mathrm{C}$ and $1 \mathrm{~h}$ post-weld tempering indicated that, according to ASTM, the ultimate tensile strength and Charpy impact energy values of welded joint were acceptable. The effect of interpass temperature on microstructure, impact toughness, and fatigue crack propagation of CA6NM joints were researched, which were welded by GTAW using AWS410NiMo filler metal [8]. The research results showed that the formation of ferrite $\delta$ under a low interpass temperature can promote an increase in impact toughness and a decrease in the fatigue crack propagation when compared with the sample welded under a higher interpass temperature. The FCAW was used to weld CA6NM steel, and the effect of post welding heat treatment on the microstructure and mechanical properties of welded joint were studied [9]. The results showed that despite the nearly identical toughness values of the weld metal for AW and PWHT samples, the PWHT material showed finely dispersed retained austenite at an amount near 10 vol.\%. It can be inferred from the above results that the welding process of CA6NM basically includes commonly used welding methods, which have achieved good results. However, in the repair process of castings, it is often impossible to repair products with satisfactory performance by welding once; therefore, multiple repair welding is necessary to meet the requirements. At present, changes in the properties of CA6NM stainless steel after repeated weld repairs, i.e., the effects on its microstructure and mechanical properties, are unknown. However, there have been relevant studies on the influence of multiple repair welding on the microstructure and properties of welded joints. Carpenter et al. [10] investigated the effect of multiple repair welding procedures on quenched and tempered steel for naval vessels. The findings showed that, compared to the original toughness, the application of multiple repeat welds or the multiple simulation of the same sub-HAZ thermal cycle did neither deteriorate toughness nor noticeably altered the final microstructure. Sun [11-15] repaired Q345C several times and tested the hardness and impact toughness of the welded joints after multiple repair welding cycles. The results indicated that, after 10 repair welding sessions, the hardness and impact energy of the welded joint decreased, but these could still meet the needs of the project. The microstructure and mechanical properties of 7N01 aluminum alloy welded joint were studied for multiple repair welds. [16] As a result, the hardness of DC CMT was weaker than the pulsed MIG, and the DC CMT could effectively reduce the hot cracking sensitivity and alleviate the degradation of joint performance. To analyze the effect of multiple repair welding on the performance of CA6NM stainless steel welded joints, this study uses GTAW to perform multiple repair welds on CA6NM stainless steel and subsequently examines and analyzes the microstructure and properties of the welded joint. The repair welding area includes the weld, the base material, and the HAZ, and the weakest position in these areas is expected to be the HAZ. Therefore, the aims of this paper are mainly the analysis of microstructure and properties of the HAZ under multiple repair welding and the exploration of the relevant mechanisms to guide subsequent production.

\section{Experimental Method}

In this study, GTAW is used to prepare the $1 \mathrm{R}$ and $2 \mathrm{R}$ specimens. The welding current is $180 \mathrm{~A}$, the welding voltage is $17 \mathrm{~V}$, and the welding speed is $85-100 \mathrm{~mm} / \mathrm{min}$. The chemical composition of CA6NM, determined by Handhold Energy Dispersive XRF spectrometer and welding wire (ER410NiMo), is shown in Table 1.

The CA6NM steel is repair-welded once and twice, respectively, and marked as $1 \mathrm{R}$ and $2 \mathrm{R}$. After the repair welding process, the test plate is processed into the corresponding test sample. The pick-up location of the performance sample is shown in Figure 1. For comparative analysis, the base material is also processed into the same test sample as the repair-welded samples, as required. The microstructure of the sample is observed by metallographic microscope (OM, Olympus BX-6). The phase composition is observed by X-ray diffraction (XRD, Shimadzu 7000). The grain orientation field is examined by emission scanning electron microscope (FESEM, Geminisem300) and transmission electron microscope (TEM, JEM-2000). The hardness of the welded joint is tested by a Rockwell hardness tester (HR-150A). The size of the Charpy impact specimen is $10 \mathrm{~mm} \times 10 \mathrm{~mm} \times 55 \mathrm{~mm}$. The impact energy is tested by an impact tester (JB-300B).

\section{Results and Discussion}

The phase composition of the repair welding area was analyzed, and the results are shown in Figure 2. It can be established from the XRD pattern of the base material region that the base material is basically composed of a Ni-Cr-Fe phase with body-centered cubic (BCC) structure. After repair welding, the phase composition in the heat-affected zone obviously changes compared with the base material. The phase composition in the HAZ includes Ni-Cr-Fe, $\mathrm{NiCx}$, and $\mathrm{Fe}_{0.64} \mathrm{Ni}_{0.36}$, whether for once-repaired weld or twice-repaired weld. The Ni-Cr-Fe phase is the matrix, and B and $\mathrm{C}$ are precipitates. In contrast, the diffraction peak 
TABle 1: Chemical composition of CA6NM and ER410NiMo (wt.\%).

\begin{tabular}{lcccccccc}
\hline & $\mathrm{C}$ & $\mathrm{Si}$ & $\mathrm{Mn}$ & $\mathrm{S}$ & $\mathrm{P}$ & $\mathrm{Cr}$ & $\mathrm{Ni}$ & $\mathrm{Mo}$ \\
\hline CA6NM & 0.04 & 0.58 & 0.60 & 0.010 & 0.020 & 13.60 & 4.10 & 0.55 \\
ER410NiMo & 0.02 & 0.40 & 0.60 & 0.002 & 0.021 & 12.10 & 4.61 & 0.47 \\
\hline
\end{tabular}

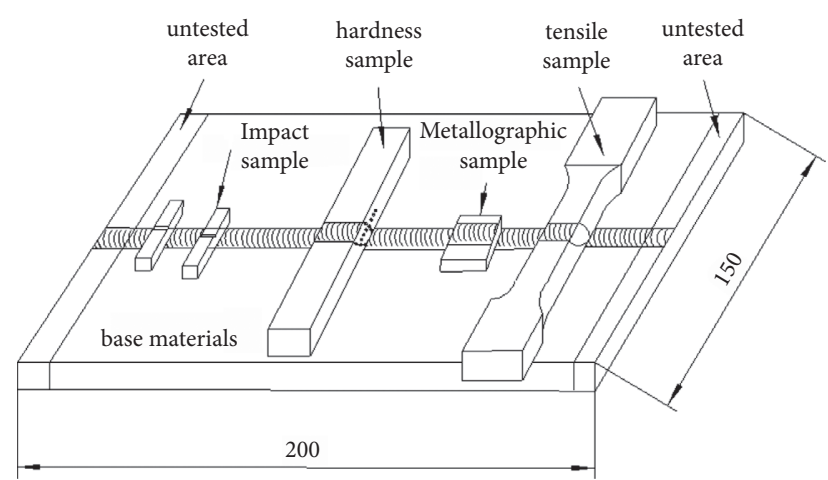

Figure 1: Schematic diagram of processed samples.

intensity of $\mathrm{NiCx}$ in the twice-repaired weld is improved to a certain extent, which indicates that the precipitation amount of $\mathrm{NiCx}$ has been increased. This phenomenon indicates that more carbides are formed in the HAZ in two repair welding cycles, which will improve the hardness of the HAZ to a certain extent.

The microstructure of welded joints with a different number of welding repairs is shown in Figure 3. In the figure, the distribution from left to right represents the base material, the heat-affected zone, and the weld, respectively. The fusion lines can be vaguely seen both in the once-repaired weld and the twice-repaired weld. The fusion line is arcshaped without obvious precipitate, which indicates a good fusion of welded joints. The microstructures of weld, heataffected zone, and base material are different because of the different action processes of welding heat input. The weld is formed by the fusion and solidification of the filling material and the base material. The microstructure of the weld is equiaxed grain, which is quite different from the lath martensite beam of the base material. The heat-affected zone (HAZ) is between the base material and the weld. The metallurgical reaction process of the heat-affected zone is complex and the microstructure morphology is very characteristic. Therefore, the heat-affected zone is usually the weak zone of the welded joint. The microstructures of the heat-affected zone in Figure 3 have limited magnification, and the difference between the two cannot be clearly observed. So, high-power metallographic analysis of the HAZ was carried out, and the results are shown in Figure 4. It can be found that the base material is still lath martensite structure, and the martensite is mainly distributed in bundles, as shown in Figure 4(a). The bundles are arranged in different directions and their structure is relatively dense. After repair welding, the martensite beam basically disappears, and the heat-affected zone is replaced by equiaxed grains. Comparing the once-repaired weld and the twicerepaired weld, the grain size of the HAZ of the twicerepaired weld is slightly smaller, and the carbide precipitation is increased. This has a positive effect on improving the performance of HAZ and enhancing the overall bearing capacity of welded joint.

In order to accurately judge the change of grain size before and after repair welding, EBSD technology is used to count the grain size, and the results are shown in Figure 5. It can be found that the grain size has changed significantly. Firstly, the size of most of the crystal grains in the three states is less than $10 \mu \mathrm{m}$. With the increasing number of repair welding procedures, the percentage of grains over $10 \mu \mathrm{m}$ in diameter decreases gradually. Secondly, the grain size of the HAZ becomes significantly refined after repair welding, and the proportion of grains smaller than $5 \mu \mathrm{m}$ exceeds $61 \%$. The proportion of grains in the HAZ less than $10 \mu \mathrm{m}$ in oncerepaired weld reaches $93.25 \%$ and that in the HAZ less than $10 \mu \mathrm{m}$ in twice-repaired weld reaches $95.53 \%$. The average grain diameter of $1 \mathrm{R}$ specimen is $5.32 \mu \mathrm{m}$, which shows a decrease of $16.7 \%$ compared to that of the base material. The average grain diameter of $2 \mathrm{R}$ specimen is $5.13 \mu \mathrm{m}$, which is $19.6 \%$ smaller than that of the base material, as shown in Table 2. The findings reveal that repair welding can refine the grains in the HAZ.

Apart from statistics on grain size, EBSD can also analyze the growth characteristics and distribution characteristics of crystals in the HAZ. The grain distribution and corresponding pole figures of the $0 \mathrm{R}$ specimen and the HAZ of the $1 \mathrm{R}$ and $2 \mathrm{R}$ specimens are shown in Figure 6. In the $0 \mathrm{R}$ specimen, the preferred texture orientation is in the (101) plane. The texture concentration density of the 0R specimen in the $\{100\},\{110\}$, and $\{111\}$ crystal plane families are shown in Figure 6(b). It can be found that the maximum texture concentration density reaches 11.48 , which appears in the $\{110\}$ crystal plane families. By observing the EBSD of the HAZ of $1 \mathrm{R}$ specimen in Figure 6(c), it can be found that the grain morphology has changed significantly, and the grains have no obvious orientation. The texture concentration density of the HAZ in the $1 \mathrm{R}$ specimen is 4.39 , which is only one third of the $0 \mathrm{R}$ specimen, and the texture randomness is stronger. Higher texture randomness will lead to more obstacles to slip and improve the toughness of materials [17-20]. There is still no obvious texture orientation in the HAZ in the $2 \mathrm{R}$ specimen, and the texture concentration density is also reduced to 3.51. This phenomenon occurs mainly because the repair welding area is re-liquefied and re-solidified during the repair welding process. This process will cause the molten pool metal to recrystallize and nucleate, causing the original grain growth to be disrupted, and the inhibition of the formation of martensite bundles with a certain orientation. In addition, since the temperature of the base metal around the repair welding area is lower, it is easy to produce a larger degree of undercooling, which further promotes the formation of equiaxed crystals. The results show that repair welding can effectively reduce the 


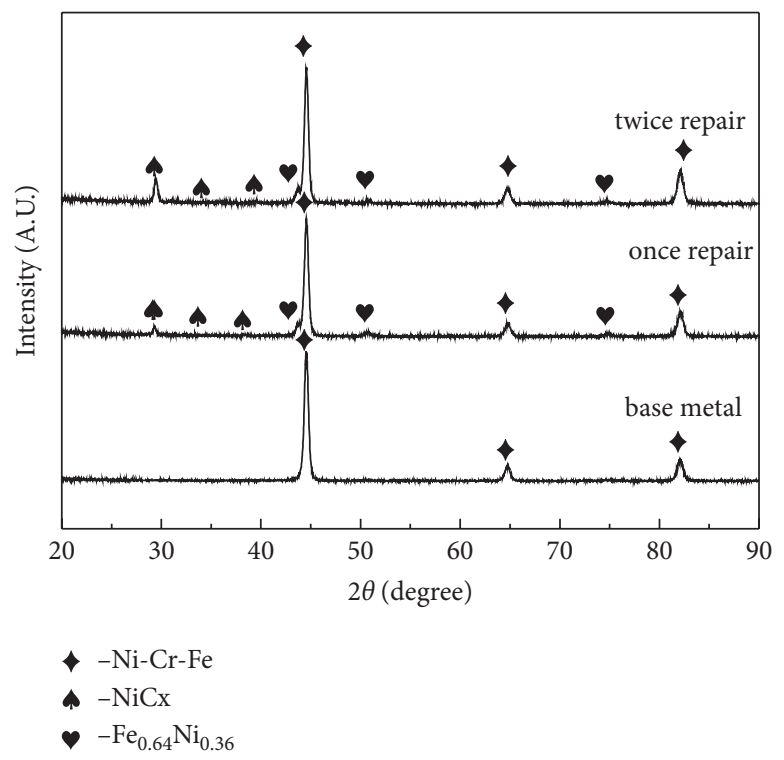

FigURE 2: XRD patterns of specimen.

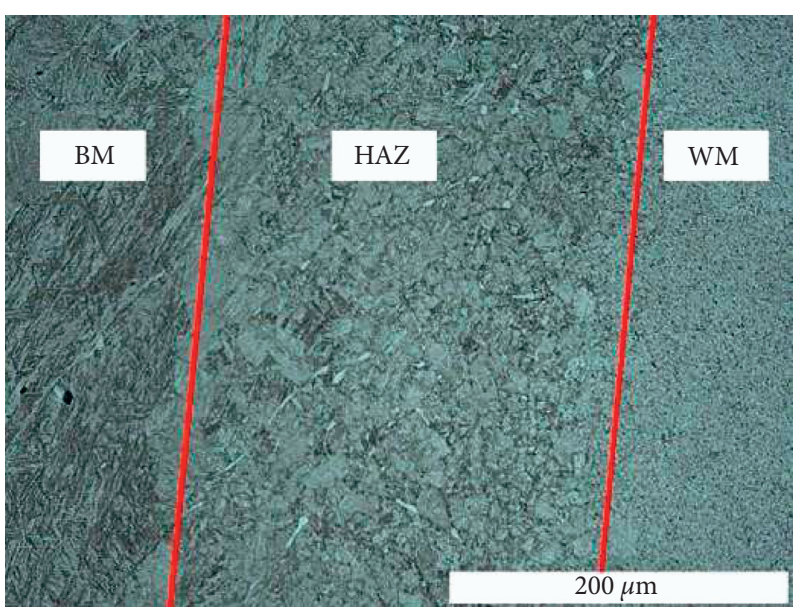

(a)

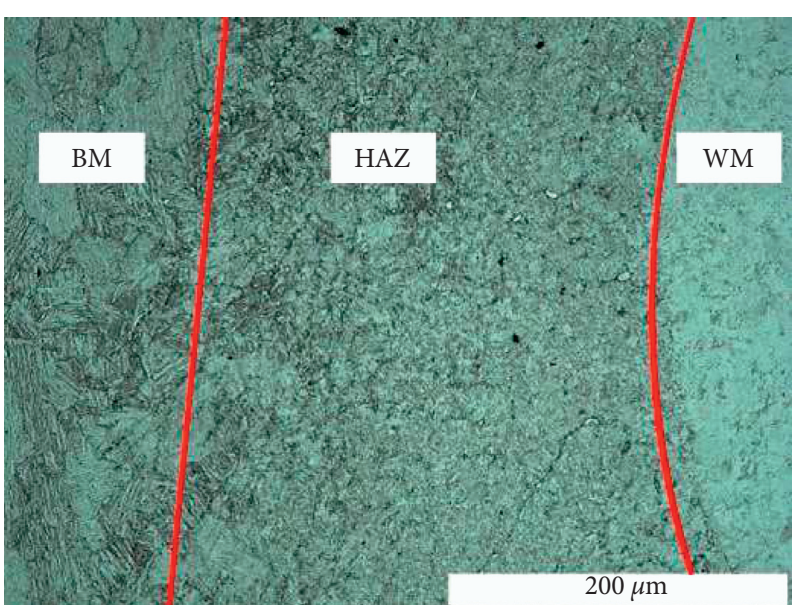

(b)

FiguRE 3: Microstructure of welded joints after a different number of welding procedures: (a) once-repaired weld and (b) twice-repaired weld.

texture concentration density, which is consistent with the research results of Hassan et al. [21].

In order to observe the crystal morphology of the HAZ under a different number of repair welds more clearly, transmission electron microscopy is performed, and the results are shown in Figure 7. Figure 7(a) shows the complete shape of lath martensite in the $0 \mathrm{R}$ specimen with a width of 200-500 $\mathrm{nm}$. The martensitic laths in the same beam are distributed in a parallel position. The martensitic beam is divided by high-angle grain boundaries. When plastic deformation occurs under force, the grain of the material will slip. If the slip zone moves to the high-angle grain boundary, it takes more energy to cross the grain boundary, thereby the strength of materials will be improved [22]. In Figure 7(b), it can be found that there are a large number of dislocations on the lath produced during the casting process. These dislocations form dislocation walls or networks, which divide the lath into different regions, but no subgrain boundaries have been formed. As seen in Figure 7(c), the morphology has changed from the original lath shape to a block shape, and the grain size of block ferrite is about $500 \mathrm{~nm}$. High-density dislocations can be detected on the grain surface, especially near the grain boundary. These dislocations are formed by the collision between adjacent grains during the growth process of the crystal and the volume change during the post-weld cooling process, which results in the change of thermal stress, and the generation of steps or stress on the crystal surface. Figure $7(\mathrm{~d})$ shows that the grain size is finer than that of the $1 \mathrm{R}$ specimen, and there are a large number of pearlite lamellae, which plays a positive role in improving the mechanical properties of the material. Twins and dislocations in the white circle can also be seen in Figure 7(d). It has been known that the grains in the HAZ of the $2 \mathrm{R}$ specimen have been refined, which leads to the increase of 


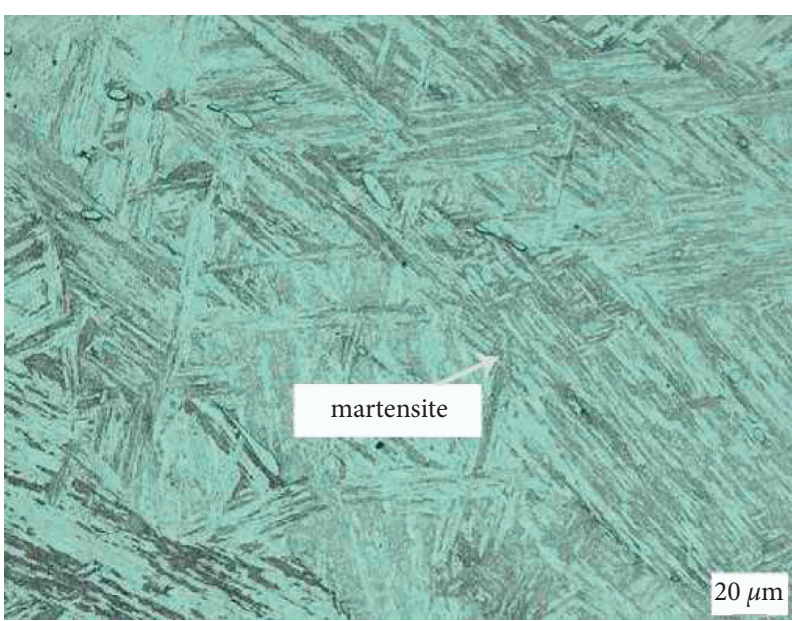

(a)

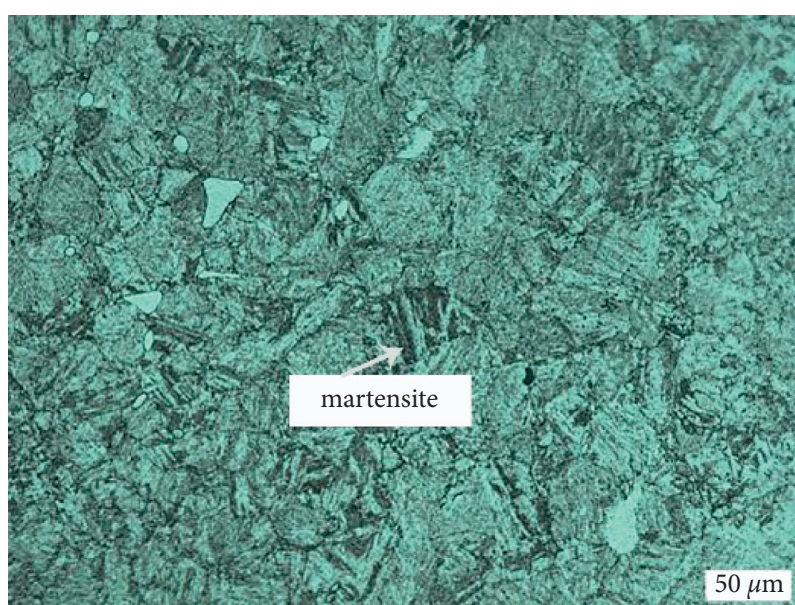

(b)

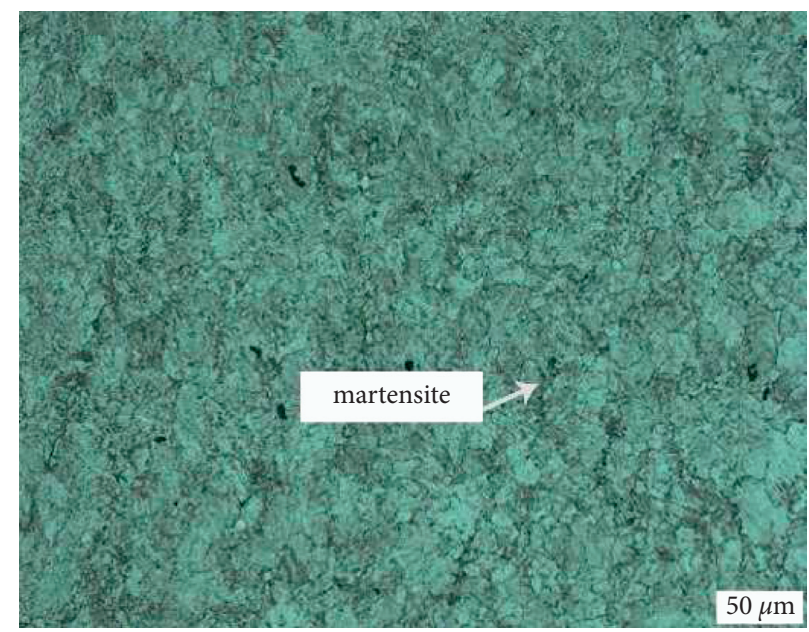

(c)

FIGURE 4: Microstructure of the heat-affected zone in welded joint between samples. (a) Base material, (b) once-repaired HAZ, and (c) twicerepaired HAZ.

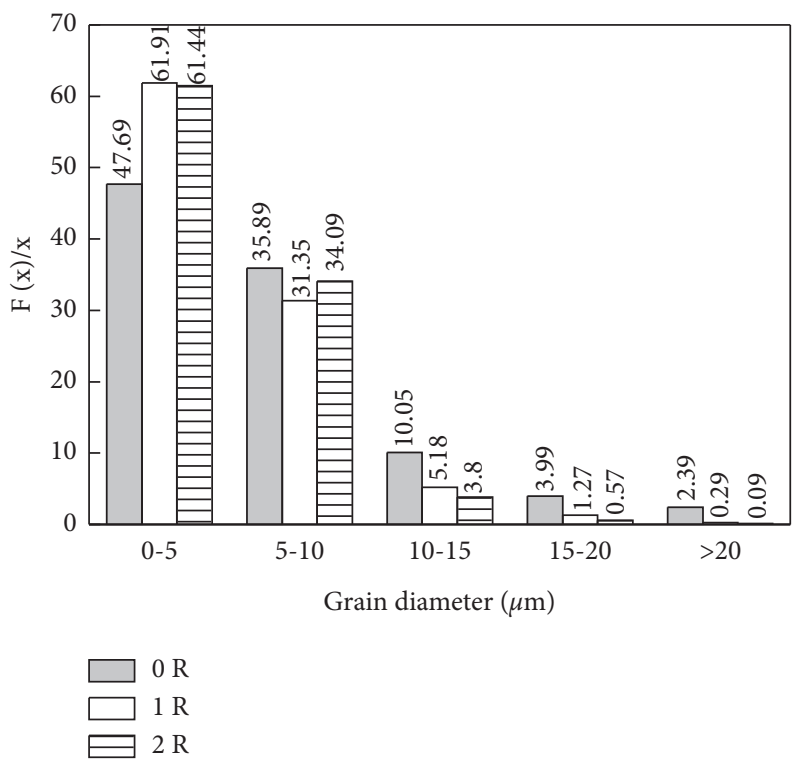

FIgURE 5: Grain size of HAZ with different numbers of repair welds. 
TABLE 2: Average diameter of grains after different number of repair welds.

\begin{tabular}{lccc}
\hline Repair times & Average diameter $(\mu \mathrm{m})$ & Average area $\left(\mu \mathrm{m}^{2}\right)$ & Number of grains \\
\hline 0 & 6.3941 & 46.544 & 627 \\
1 & 5.3275 & 28.214 & 1024 \\
2 & 5.1378 & 25.069 & 1053 \\
\hline
\end{tabular}

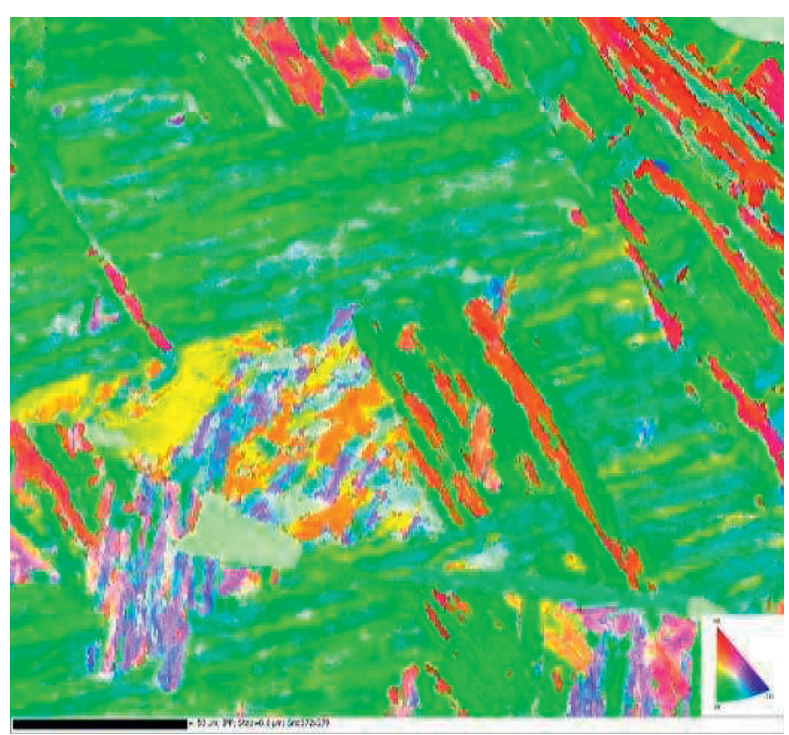

(a)

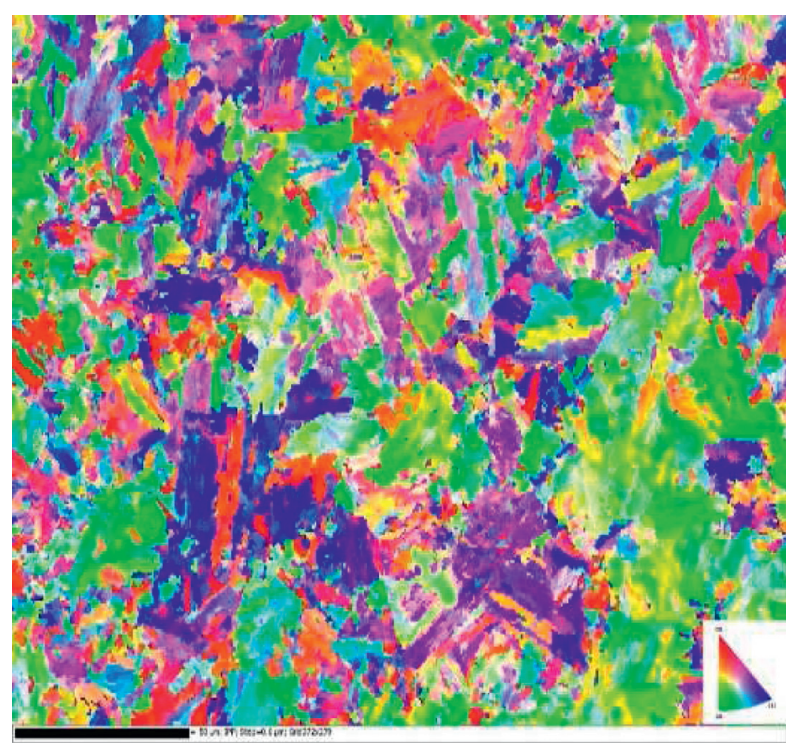

(c)
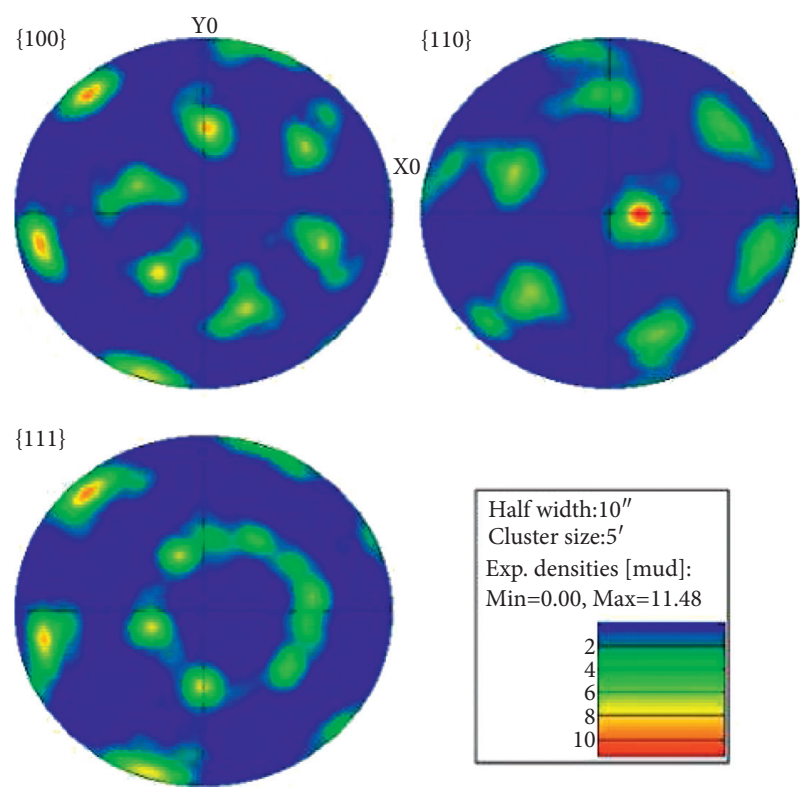

(b)
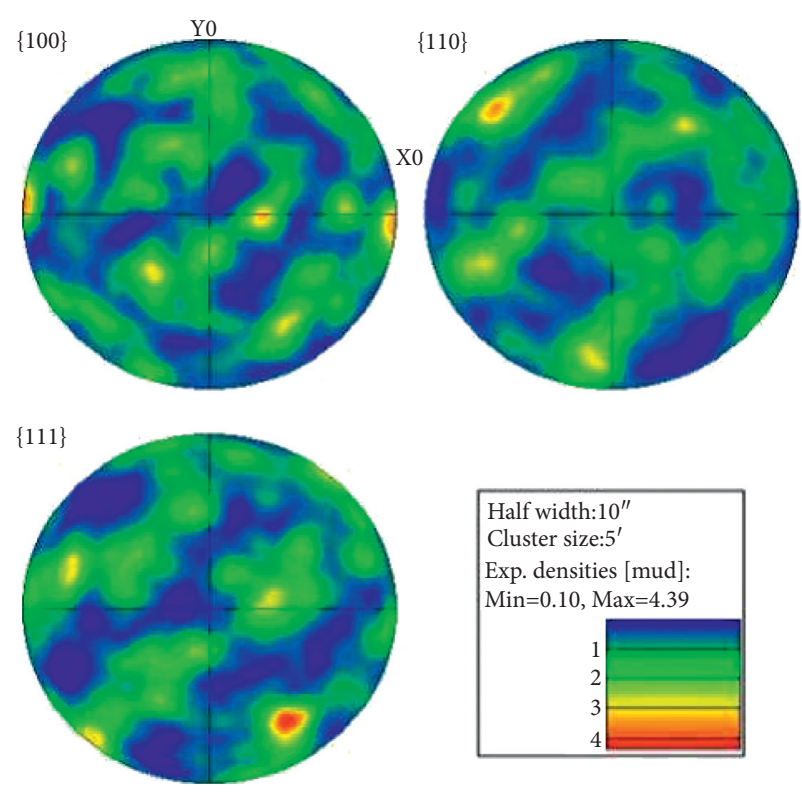

(d)

FIGURE 6: Continued. 


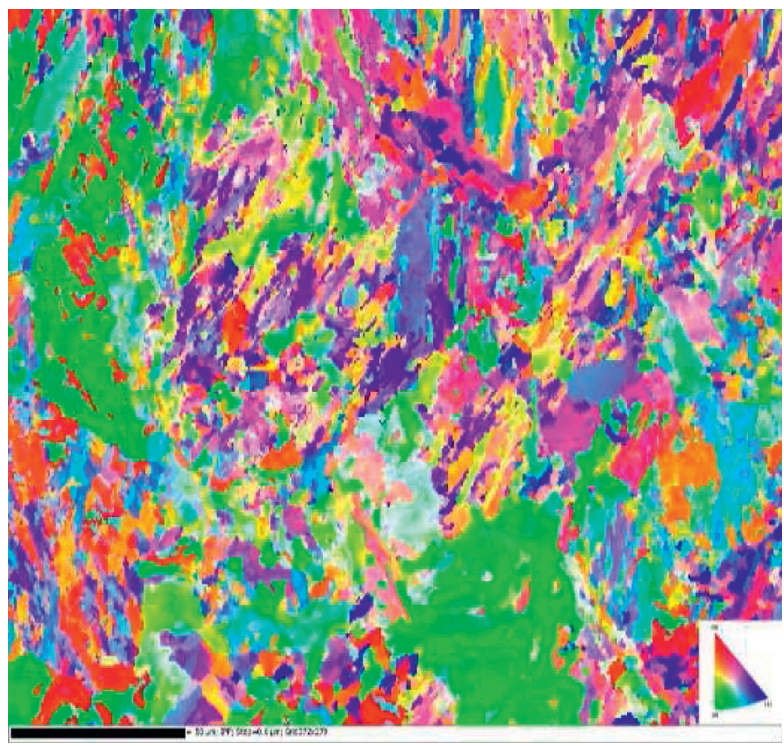

(e)
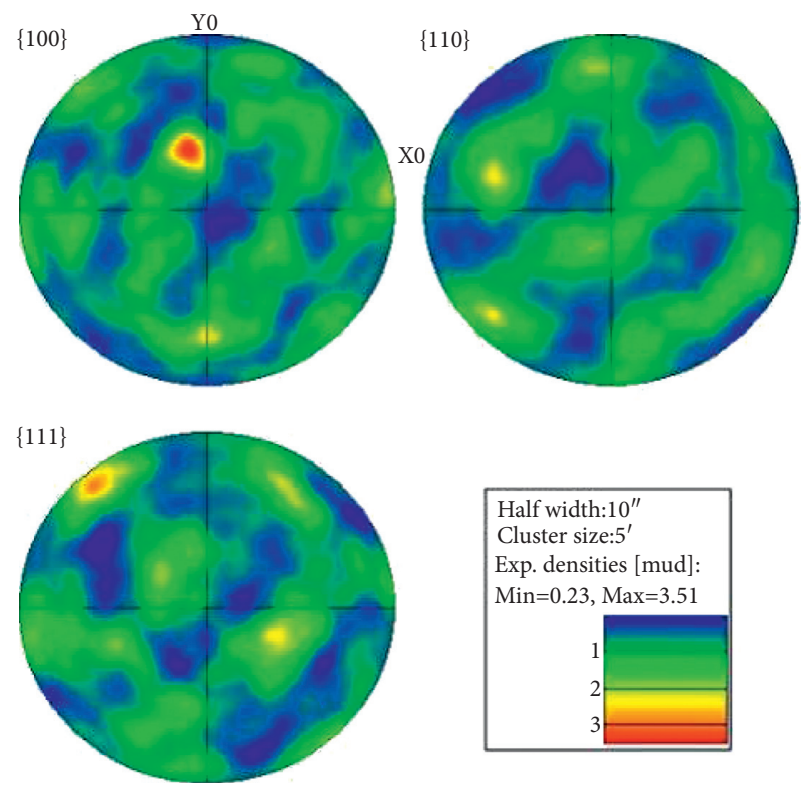

(f)

FIGURE 6: EBSD morphology and pole figure of specimen. (a) EBSD morphology of 0R specimen. (b) Pole figure of 0R specimen. (c) EBSD morphology of $1 \mathrm{R}$ specimen. (d) Pole figure of $1 \mathrm{R}$ specimen. (e) EBSD morphology of $2 \mathrm{R}$ specimen. (f) Pole figure of $2 \mathrm{R}$ specimen.

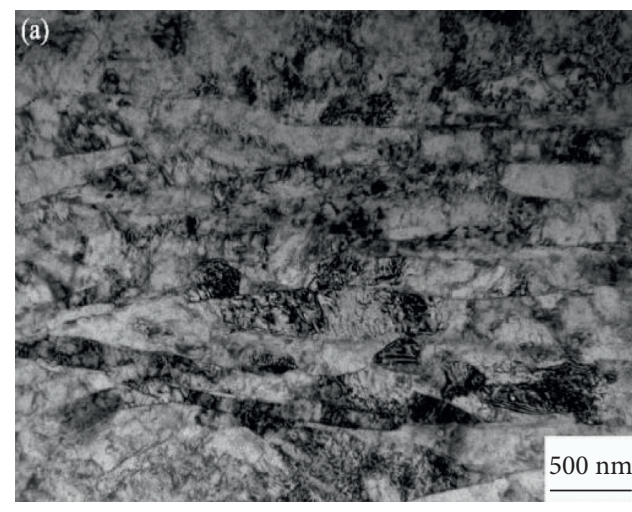

(a)

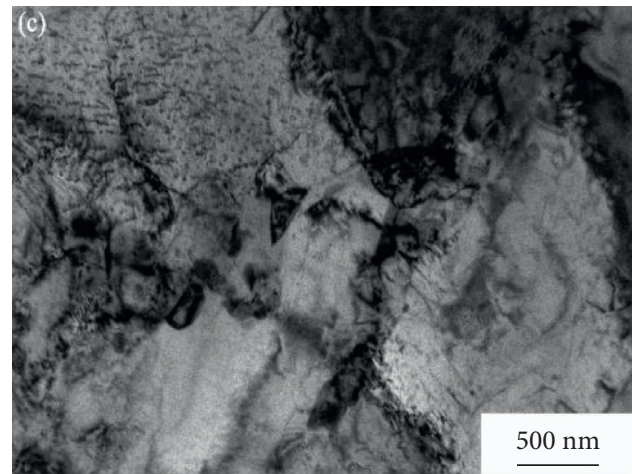

(c)

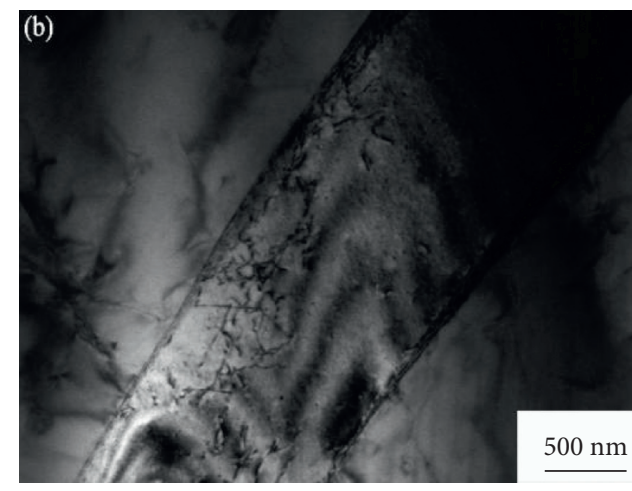

(b)

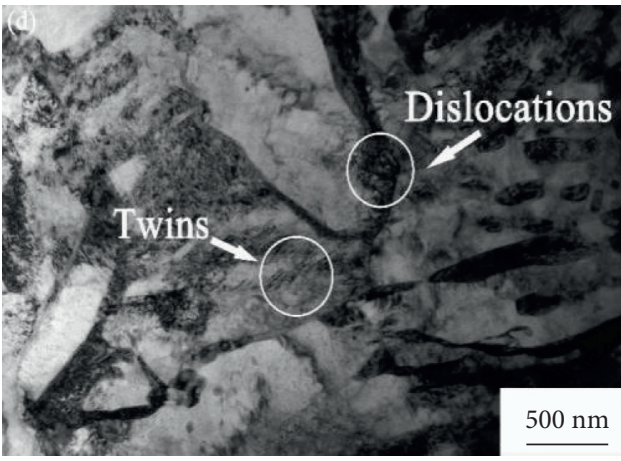

(d)

Figure 7: Morphology of microstructure by TEM. (a) 0R specimen (15000X). (b) 0R specimen (20000X). (c) 1R specimen (25000X). (d) 2R specimen (20000X). 


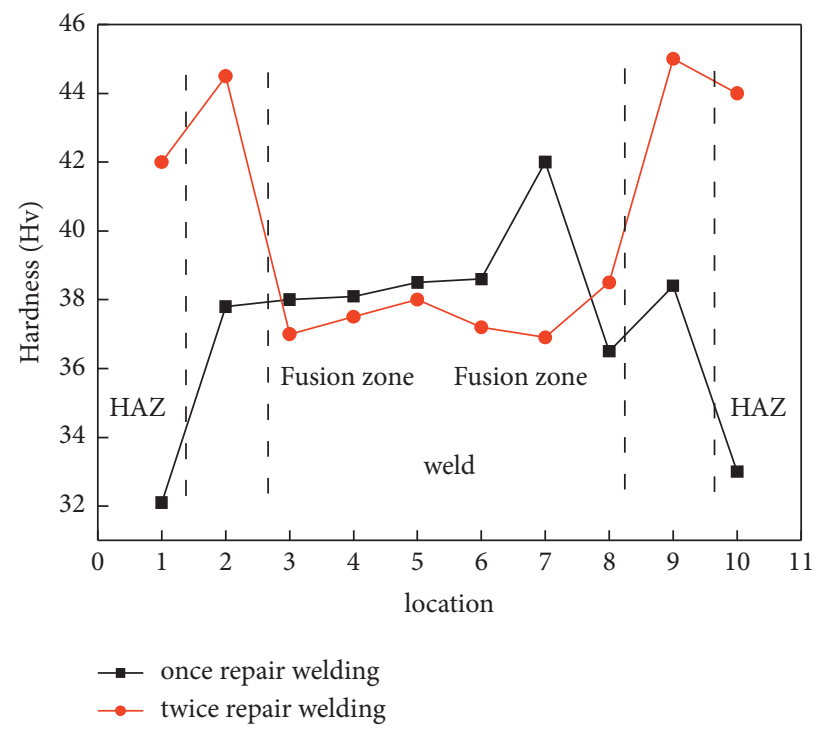

FIGURE 8: Hardness of welded joint with a different number of repair welding times.

density and energy of grain boundary. At the same time, the increase of plastic deformation resistance caused by the obstruction of grain boundary to dislocation movement will enhance the mechanical properties of the HAZ of the $2 R$ specimen.

In view of the direct relationship between structure and performance, the change of microstructure will inevitably affect the macromechanical properties of the material. To analyze the changes in the performance of the welded joints under different repair welding times, the hardness of the welded joints was first tested and analyzed, and the results are shown in Figure 8. It can be seen that the hardness data of the weld are relatively uniform, and the hardness of the HAZ changes greatly. For the hardness of the weld, the once-repaired weld shows a slightly larger value than the twice-repaired weld, and for the hardness of the HAZ, the twice-repaired weld is significantly greater than that of the once-repaired weld. To more clearly reflect the effect of repair welding times on the hardness of the HAZ, the surface and profile hardness of the HAZ were tested, with the results shown in Figure 9. For the surface hardness of the HAZ, the hardness of $1 \mathrm{R}$ is opposite to the hardness of $0 R$, and it is significantly lower than the hardness of $2 R$, as shown in Figure 9(a). With respect to the profile of the HAZ, the difference in hardness between the three states is still quite obvious. The hardness of $1 \mathrm{R}$ is higher than that of $2 R$, and the hardness of $2 R$ is greater than that of $0 R$, shown as Figure 9(b). The average surface hardness of the HAZ under $1 \mathrm{R}$ and $2 \mathrm{R}$ is $0.45 \%$ and $26.58 \%$ higher, and the average profile hardness is $8.08 \%$ and $30.75 \%$ higher than that of the $0 \mathrm{R}$ specimen, respectively.

The impact energy curves of the HAZ under a different number of repair welding times are shown in Figure 10. There are three curves in the figure, which represent the variation of the impact toughness of HAZ with temperature under a different number of repair welding times. As the test temperature decreases, the impact energy of the HAZ shows a downward trend, which does not correlate with the number of repair welding times. This change law reflects the basic properties of the material. As the temperature decreases, the toughness of the material gradually diminishes until brittle fracture occurs. Under the same temperature conditions, the impact energy values of the once-repaired weld and the twice-repaired weld are not much different, but are still higher than that of the $0 \mathrm{R}$.

Impact fracture contains a lot of information, which is beneficial to explain the change of material impact toughness. For this reason, this paper also detects and analyzes the fracture of the impact sample. However, due to the large number of impact samples in this test, only representative $20^{\circ} \mathrm{C}$ and $-60^{\circ} \mathrm{C}$ are selected for comparison. The results are shown in Figure 11. It can be seen from the figure that, at $20^{\circ} \mathrm{C}$, there are a large number of dimples in the impact fracture, and the fracture mode of the sample is ductile fracture, which is consistent with the impact energy data, as shown in Figures 10(a)-10(c). When the experimental temperature is $-60^{\circ} \mathrm{C}$, the impact fracture changes very obviously, and a large number of cleavage planes or quasicleavage planes appear at the fracture, as shown in Figures $10(\mathrm{~d})-10(\mathrm{f})$. This phenomenon is consistent with the deterioration of impact toughness. Comparing the fracture morphology under a different number of repair welding times, it can be found that whether it is 20 degrees or -60 degrees, the number of dimples in the $1 \mathrm{R}$ and $2 \mathrm{R}$ repair welding fractures is higher than $0 \mathrm{R}$, and the size is smaller. This should be the reason why the impact energy of $1 \mathrm{R}$ and $2 \mathrm{R}$ is higher than $0 \mathrm{R}$. During welding, the weld zone is heated above the liquidus line to melt the filler and part of the base metal to form a molten pool. Since the HAZ is between the base metal and the weld, its temperature is not as high as that of the weld, but its temperature is also heated to above $\mathrm{A}_{\mathrm{C} 3}$. At this time, the structure of the HAZ is also completely austenitized and then begins to cool gradually and solidify. Due to the small volume of the molten pool and 


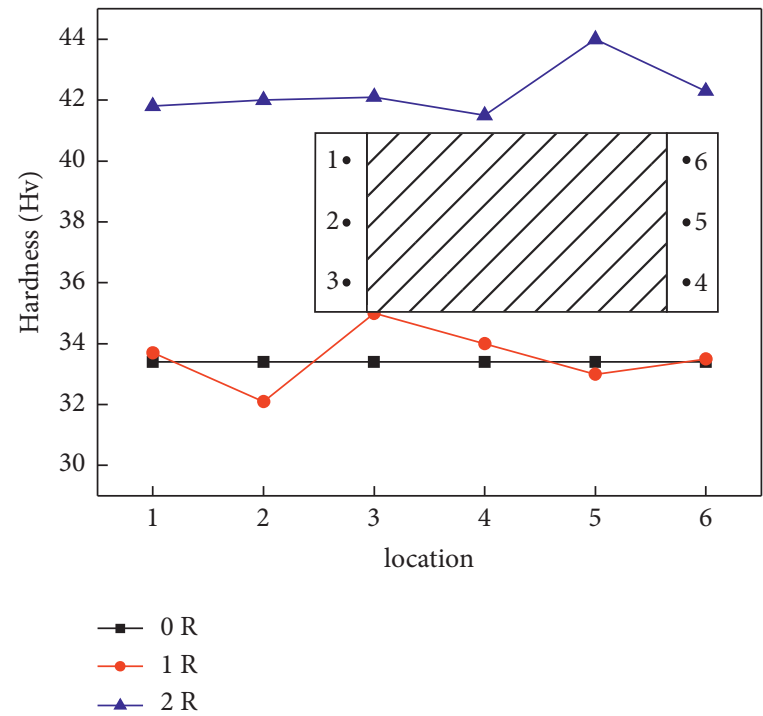

(a)

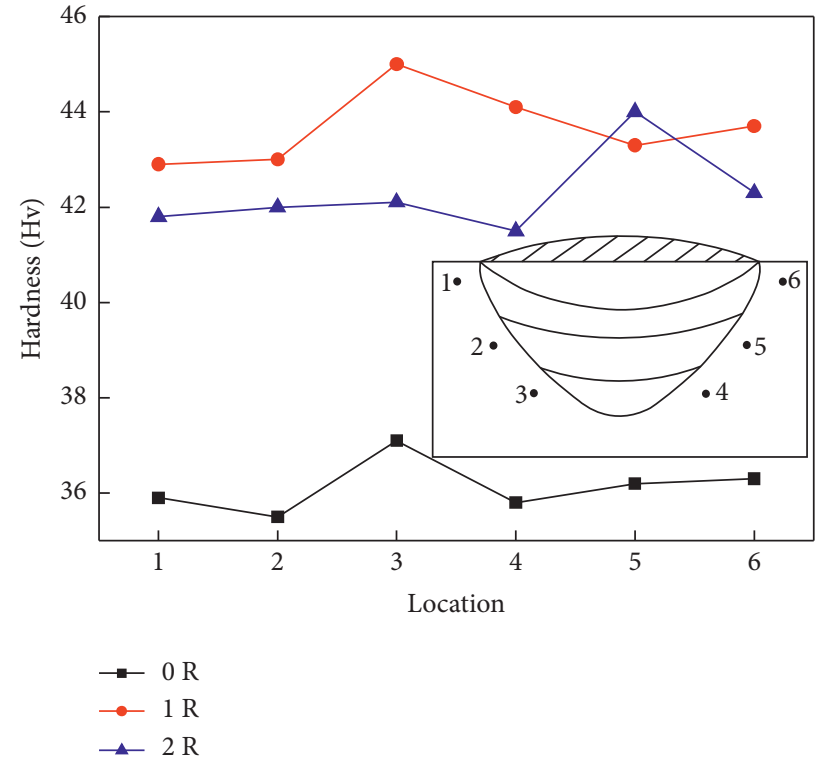

(b)

Figure 9: Hardness of HAZ. (a) Hardness of surface. (b) Hardness of profile.

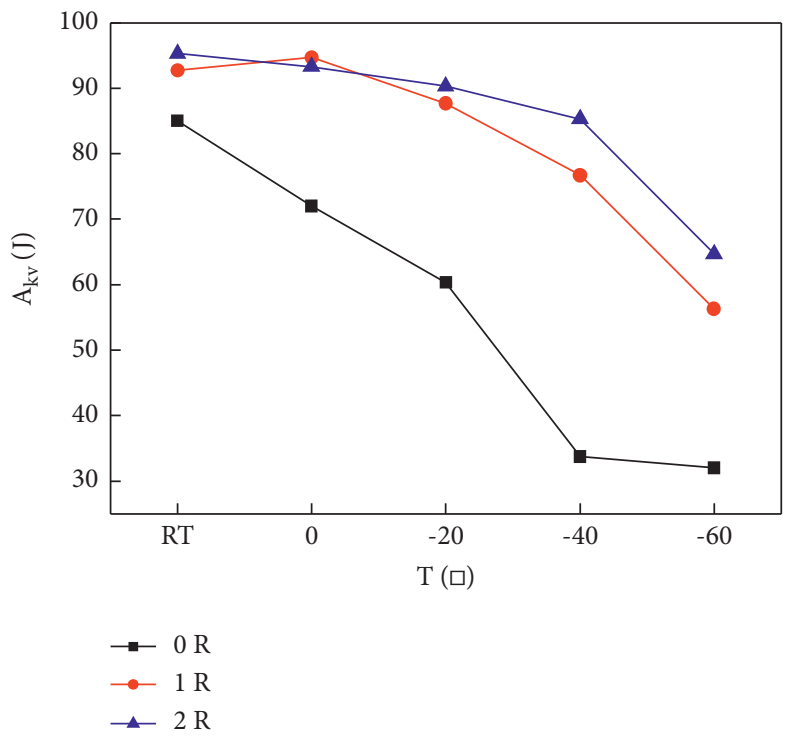

Figure 10: Impact energy of repair welding area.

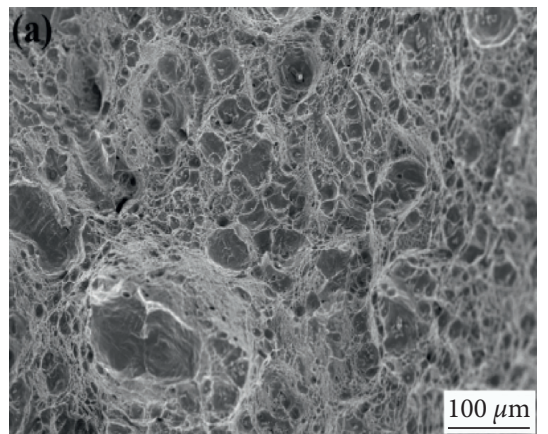

(a)

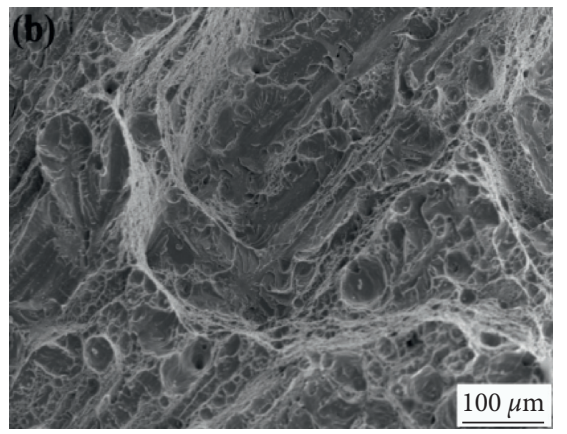

(b)

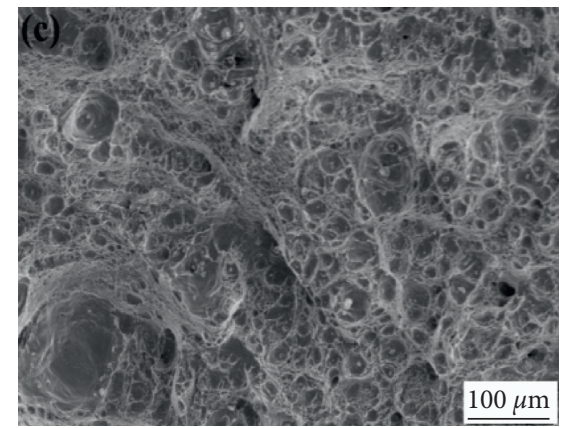

(c)

FIgURE 11: Continued. 


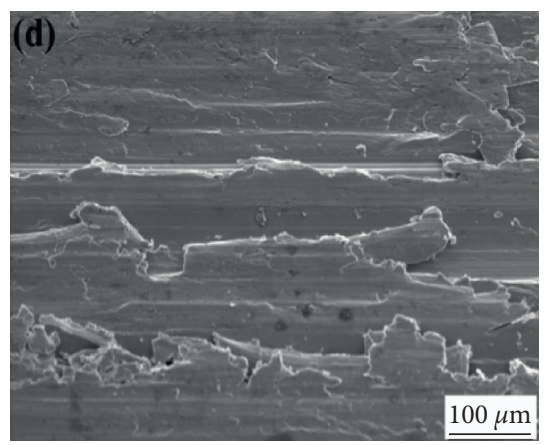

(d)

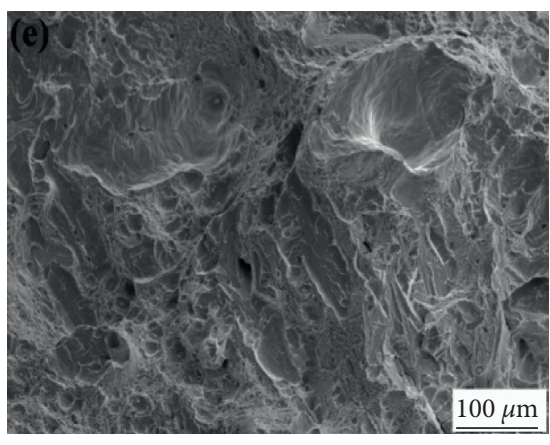

(e)

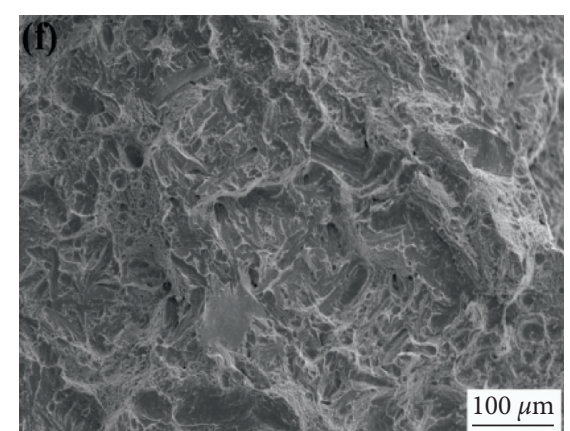

(f)

Figure 11: Impact fracture of the heat-affected zone. (a) $0 \mathrm{R} 20^{\circ} \mathrm{C}$, (b) $1 \mathrm{R} 20^{\circ} \mathrm{C}$, (c) $2 \mathrm{R} 20^{\circ} \mathrm{C}$, (d) $0 \mathrm{R}-60^{\circ} \mathrm{C}$, (e) $1 \mathrm{R}-60^{\circ} \mathrm{C}$, and (f) $2 \mathrm{R}-60^{\circ} \mathrm{C}$.

the fast heat dissipation rate, the liquid molten pool and the HAZ exist for a shorter period, and the nucleation and growth process of crystal grains is different from the traditional as-cast state. The degree of undercooling in the HAZ is large, and the grain growth time is short. This process is equivalent to normalize or refine the grain, consistently with the research results of Vega. O.E. [23-26] Thus, hardness and toughness are improved through a fine grain strengthening mechanism. These are in good agreement with the grain size data in Figure 5. During the second repair welding process, the previous weld pass is reheated. At this time, the secondary repair welding is relative to the annealing treatment of the original primary repair welding bead. This can relieve stress and homogenize the structure, which can in turn improve the toughness of the material. Therefore, the dual role of repair welding twice in grain refinement strengthening and remelting annealing is more beneficial to the improvement of toughness and strength.

\section{Conclusions}

In this study, the microstructure and mechanical properties of the CA6NM stainless steel heat-affected zone under a different number of repair welding times have been tested and analyzed, and the evolution of the microstructure has been studied. Based on the analysis of the above data, the following conclusions are drawn:

(1) Repair welding changes the phase composition of CA6NM. In addition to the original as-cast structure of $\mathrm{Ni}-\mathrm{Cr}-\mathrm{Fe}$, the repair welding zone also contains carbide precipitation $\mathrm{NiCx}$ and second-phase $\mathrm{Fe}_{0.64} \mathrm{Ni}_{0.36}$. The precipitation of carbide and second phase increase the strength and hardness of the welded joint.

(2) After repair welding, the martensite beam basically disappears, and the heat-affected zone is replaced by equiaxed grains. Compared with the once-repaired weld and the twice-repaired weld, the grain size of the HAZ of the twice-repaired weld is slightly smaller, and the carbide precipitation is increased. This has a positive effect on improving the performance of HAZ and improving the overall bearing capacity of welded joint.
(3) The texture of repair welding area is no longer directional and showing crystal orientation behavior, and the texture density decreased by $69.43 \%$. Dislocations and lamellar pearlites are detected, and the grain refining effect is more obvious. The average grain diameter of $1 \mathrm{R}$ and $2 \mathrm{R}$ specimen shows $16.7 \%$ and $19.6 \%$ reduction, respectively.

(4) The increase of hardness has little fluctuation, but material toughness has been greatly improved when the CA6NM is repair-welded once or twice. The average surface hardness of the HAZ under $1 \mathrm{R}$ and $2 \mathrm{R}$ is $0.45 \%$ and $26.58 \%$ higher than that of the $0 \mathrm{R}$, respectively, which is mainly due to the carbide phase in the HAZ. The grain refinement strengthening and remelting annealing effects are more beneficial to improving material toughness in the twice-repaired weld.

\section{Data Availability}

No data were used to support this study.

\section{Conflicts of Interest}

The authors declare that there are no conflicts of interest with any financial organizations regarding the material reported in this manuscript.

\section{References}

[1] J. H. Liu, H. Dong, R. Zhu, and S. Q. Li, "Study on transformation of $\mathrm{CaO}-\mathrm{Al}_{2} \mathrm{O}_{3}-\mathrm{SiO}_{2}-\mathrm{MgO}$ system inclusions in ZG06Cr13Ni4Mo stainless steel," Journal of Iron and Steel Research, vol. 18, no. S2, pp. 341-346, 2011.

[2] V. I. Gladshtein, "Improvement of repair weld quality in lowalloy steel turbine casing components," Power Technology and Engineering, vol. 47, no. 1, pp. 61-67, 2013.

[3] T. Schuchardt, S. Müller, and K. Dilger, "Remanufacturing of die casting dies made of hot-work steels by using the wirebased electron-beam welding with an in situ heat treatment," Welding in the World, vol. 63, no. 6, pp. 1669-1679, 2019.

[4] C. V. Roa, J. A. Valdes, F. Larrahondo, and S. A. Rodríguez, "Comparison of the resistance to cavitation erosion and slurry erosion of four kinds of surface modification on 13-4 CA6NM 
hydro-machiney steel," Journal of Materials Engineering and Performance, vol. 30, p. 6, 2021.

[5] A. Allenstein, C. Lepienski, A. D. A. Buschinelli, and S. F Brunatto, "Improvement of the cavitation erosion resistane for low-temperature plasma nitrided CA6NM martensitic stainless steel," wear, vol. 309, no. 1-2, pp. 159-165, 2014.

[6] S. Sarafan, P. Wanjara, H. Champliaud, and D. Thibault, "Characteristics of an autogenous single pass electron beam weld in thick gage CA6NM steel," International Journal of Advanced Manufacturing Technology, vol. 78, no. 9-12, pp. 1523-1535, 2015.

[7] F. Mirakhorli, X. Cao, X.-T. Pham, P. Wanjara, and J.-L. Fihey, "Post-weld tempered microstructure and mechanical properties of hybrid laser-arc welded cast martensitic stainless steel CA6NM," Metallurgical and Materials Transactions B, vol. 47, no. 6, pp. 3245-3256, 2016.

[8] R. R. de Gouveia, A. G. M. Pukasiewicz, A. R. Capra, S. L. Henke, and P. C. Okimoto, "Effect of interpass temperature on microstructure, impact toughness and fatigue crack propagation in joints welded using the GTAW process on steel ASTM A743-CA6NM," Welding International, vol. 29, no. 6, pp. 433-440, 2015.

[9] R. d. P. Silva, M. I. S. T. Faria, L. F. C. B. d. Almeida, C. A. Nunes, D. Vieira, and W. Borges Júnior, "Microstructure and mechanical properties of ASTM A743 CA6NM steel welded by FCAW process," Materials Research, vol. 20, no. 6, pp. 1622-1629, 2017.

[10] K. R. Carpenter, P. Dissanayaka, Z. Sterjovski, and H Li, “The effect of multiple repair welds on a quenched and tempered steel for naval vessels," Welding in the World, vol. 65, pp. 1-16, 2021.

[11] D. P. Koistinen and R. E. Marburger, "A general equation prescribing the extent of the austenite-martensite transformation in pure iron-carbon alloys and plain carbon steels," Acta Metallurgica, vol. 7, no. 1, pp. 59-60, 1959.

[12] Z. Gao, C. Wang, and Y. Liu, "Evaluation of cavitation erosion-corrosion process of Q235 and ZG06Cr13Ni4Mo with various applied potentials," International Journal of Electrochemical Science, vol. 10, no. 8, pp. 6487-6499, 2015.

[13] Y. Yin, P. Kang, R. Zhang, Lu Chao, X. Mengzhi, and Z. Yuan, "Effect of heat treatment on microstructure and properties of VG10 and 3Cr13 dissimilar welded joints," China Welding, vol. 30, no. 01, pp. 21-29, 2020.

[14] H. T. Yu, W. Z. Ming, and Y. G. Hui, "Welding quality control of large francis runner in baihetan hydropower station," Electromechanical technology of hydropower station, vol. 44, no. 1, pp. 50-52, 2021.

[15] W. Sun, "Effect of multiple repair welding on mechanical properties of Q345C steel welded joints," Welding technology, vol. 49, no. 5, pp. 39-42, 2020.

[16] Z. Liang, Y. Li, S. Zhao, and D Wang, "Multiple repair welding of 7N01 alumimum alloy with pulsed MIG and DC CMT welding," Transactions fo the china welding institution, vol. 35, pp. 27-32, Article ID 201435, 2014.

[17] Y. Chino, K. Sassa, A. Kamiya, and M Mabuchi, "Enhanced formability at elevated temperature of a cross-rolled magnesium alloy sheet," Materials Science and Engineering A, vol. 441 , no. 1 , pp. 349-356, 2006

[18] D. Thibault, P. Bocher, M. Thomas, M Gharghouri, and M Côté, "Residual stress characterization in low transformation temperature $13 \% \mathrm{Cr}-4 \% \mathrm{Ni}$ stainless steel weld by neutron diffraction and the contour method," Materials Science and Engineering A, vol. 527, no. 23, pp. 6205-6210, 2010.
[19] K. R. Carpenter, P. Dissanayaka, Z. Sterjovski et al., "The effects of multiple repair welds on a quenched and tempered steel for naval vessels," Welding in the World, vol. 65, no. 10, pp. 1997-2012, 2021.

[20] M. Shojaati, S. F. Kashani Bozorg, M. Vatanara, M. Yazdizadeh, and M. Abbasi, "The heat affected zone of X20Cr13 martensitic stainless steel after multiple repair welding: microstructure and mechanical properties assessment," International Journal of Pressure Vessels and Piping, vol. 188, no. 3, Article ID 104205, 2020.

[21] A. J. Hassan, T. Boukharouba, D. Miroud, and T NacerEddine, "Evolution of microstructural and mechanical properties of AISI 316 during continuous drive friction welding process," China Welding, vol. 29, no. 4, pp. 7-12, 2021.

[22] Y. Yoshida, L. Cisar, S. Kamado, and Y. Kojima, "Effect of microstructural factors on tensile properties of an ECAEprocessed AZ31 magnesium alloy," Materials Transactions, vol. 44, no. 4, pp. 468-475, 2003.

[23] T. A. Davis, L. Bichler, F. D’Elia, and N. Hort, “Effect of TiBor on the grain refinement and hot tearing susceptibility of AZ91D magnesium alloy," Journal of Alloys and Compounds, vol. 759, pp. 70-79, 2018.

[24] J. W. Cahn and J. E. Taylor, "A unified approach to motion of grain boundaries, relative tangential translation along grain boundaries, and grain rotation," Acta Materialia, vol. 52, no. 16, 2004.

[25] O. E. Vega, J. M. Hallen, A. Villagomez, and A. Contreras, "Effect of multiple repairs in girth welds of pipelines on the mechanical properties," Materials Characterization, vol. 59, no. 10, pp. 1498-1507, 2008.

[26] M. Kang, M. Jiang, S. Sridar, W Xiong, Z Xie, and J Wang, "Effect of multiple repair welding on crack susceptibility and mechanical properties of inconel 718 alloy casting," Journal of Materials Engineering and Performance, vol. 31, no. 17, pp. 1-8, 2021. 